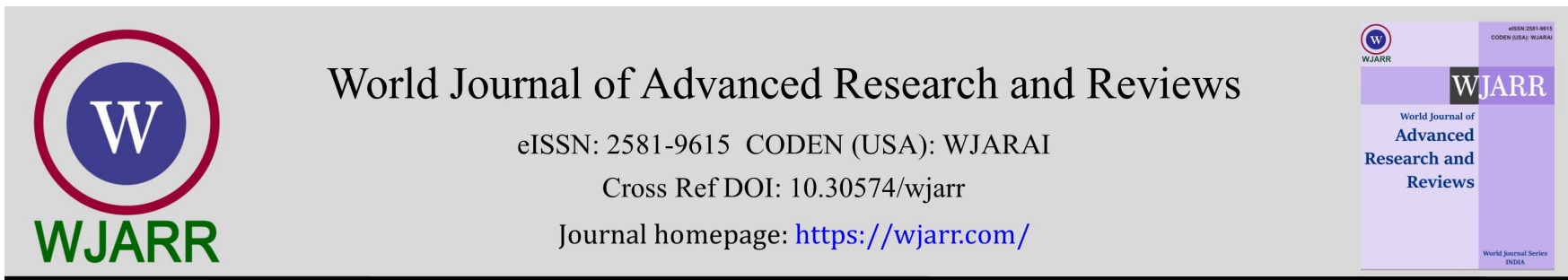

(RESEARCH ARTICLE)

Check for updates

\title{
Determination of cholesterol and fatty acid content of commercially sold edible vegetable oils around Dire Dawa, Adama and Addis Ababa, Ethiopia
}

\author{
Zelalem Gizachew Admassie 1, ${ }^{*}$, Jibrel Abdulkadir Eman ${ }^{2}$ and Sisay Awoke Endalew ${ }^{3}$ \\ ${ }^{1}$ Ethiopian Biotechnology Institute, Addis Ababa, Ethiopia. \\ 2 Dire Dawa University, Department of Chemistry, Dire Dawa, Ethiopia. \\ ${ }^{3}$ Wollo University, Department of Chemistry, Wollo, Ethiopia.
}

World Journal of Advanced Research and Reviews, 2021, 10(02), 044-056

Publication history: Received on 05 March 2021; revised on 16 April 2021; accepted on 20 April 2021

Article DOI: https://doi.org/10.30574/wjarr.2021.10.2.0147

\begin{abstract}
The fatty acids, cholesterol compositions and the ratio between unsaturated and saturated fatty acids are important parameters for the determination of the nutritional value of certain oils. Most oils sold in our markets are claimed they are cholesterol- free and their fatty acid profile is unknown. To determine the cholesterol and fatty acid profile of commercially sold vegetable oils in three places, twelve oil samples were analyzed for their cholesterol and fatty acid compositions. Cholesterol was detected in most sample oils except in nigger seed and peanut oils. Locally produced Sunflower oil has significantly $(\mathrm{p}<0.05)$ highest cholesterol concentration $(24.31 \pm 0.85)$ while Modjo oil has the least concentration $(0.78 \pm 0.16 \mathrm{mg} / \mathrm{l})$. High saturated fatty acids were found in palm oil (43.87) with predominant presence of palmitic acid. Oleic acid (C16:0) is the predominant one in sunflower oil. Hamaressa and Modjo oils contained 46.12\%, 16.7\% Erucic acid (C20:1) respectively. Linoleic acid (C18:2 6c) was predominant in soybean oils (52.45-59.54\%), corn oil (61.73\%) and sunflower oil (43.54\%). The highest percentage composition of alpha-linolenic acid was found in Hamaressa oil (1.27\%) followed by Modjo oil (0.5\%). Sesame, peanut and sunflower ( high oleic acid) oils were found to be better for salad and cooking purposes than other oils due to lower saturated and higher monounsaturated fatty acid contents. In general, the research output disclosed the quantity of cholesterol detected in sample oils contradicts the label of cholesterol claimed by most of the producers and marketers.
\end{abstract}

Key word: cholesterol, fatty acid, nigger seed oil, sesame oil and corn oil

\section{Introduction}

\subsection{Background of the study}

Oil is a very important resource, much in demand everywhere in the world and is used in a variety of ways [1]. Edible vegetable oils are considered a concentrated source of energy for human beings and carriers of oil-soluble vitamins which supply the essential fatty acids that are required for a wide range of biological and physiological functions.

Oils are naturally occurring esters of long straight-chain carboxylic acids. They belong to the saponifiable group of lipids. The saponifiable lipids contain ester groups (oil, fat, waxes and phospholipids) and react with hot sodium hydroxide solutions undergoing hydrolysis. On the other hand, the unsaponifiable lipids having no ester group include steroids, prostaglandins and leukotrienes. Steroids are minor components of all-natural fats and oils and comprise most of the unsaponifiable matters; the remainder consists essentially of hydrocarbons. It may be derived from plant (phytosterols) or animals (zoosterol's) sources [2, 3].

\footnotetext{
${ }^{*}$ Corresponding author: Zelalem Gizachew

Ethiopian Biotechnology Institute, Addis Ababa, Ethiopia.
}

Copyright (C) 2021 Author(s) retain the copyright of this article. This article is published under the terms of the Creative Commons Attribution Liscense 4.0. 
Sterols are high melting, colourless, heat-stable, and relatively inert compounds. They are widely distributed and are important in cell membranes. The predominant zoosterol is cholesterol. Every animal cell, both human and non-human, contains cholesterol. It is important in some cell functions and the liver produces all of the cholesterol the body needs. But there is no need to consume cholesterol in our diet. Cholesterol in food increases the level of Low-Density Lipoproteins (LDLs).

Edible oils are constitutes of triacylglycerol molecules, mainly formed by unsaturated (oleic, linoleic, linolenic acids etc.) and saturated fatty acids (myristic, palmitic, stearic acids etc.) esterified to Glycerol units [4]. They can be formed from a single fatty acid that could be esterified up to three times into glycerol backbone, or at least by three different ones. An even number of carbon atoms, from 16 to 18, with a single carboxyl group, is the most common. Some other minor fatty acids may be present in the same vegetable sources, including a small amount of branched-chain, cyclic and odd number straight-chain acids. The unsaturated fatty acids may have one double bond (monosaturated) or have more than one cis-methylene interrupted double bond [5].

Vegetable oils are one of the main components of human diets, comprising about $25 \%$ of average caloric intake. The ratio of saturated to unsaturated fatty acids is a factor for normal human nutrition. While high levels of saturated fatty acids are desirable to increase oil stability, on the other hand, nutritionally they become undesirable, because high levels of saturated fatty acids are frequently considered to have influenced by increasing the concentration of low-density lipoproteins (LDL), affecting the ratio of LDL to HDL (high-density lipoproteins), promoting clotting and vascular smooth muscle proliferation [6].

Diet with increasing intake of linoleic and linolenic acids increases HDL-cholesterol and decreases LDH-cholesterol, while higher intake of oleic acid decreases LDL-cholesterol but does not affect HDL-cholesterol levels [7]. However, while high levels of polyunsaturated fatty acids are important to the adequate ratio of LDL to HDL-cholesterol, these fatty acid becomes more susceptible to oxidation, even by in vivo peroxidation, resulting in several oxidation products, and many of them result in a quality reduction, improving undesirable flavour compounds, generating many toxic effects such as cell injuries, plaque formation, cell membrane cytotoxicity and coronary heart disease [8].

In Ethiopia, where several tons of food items composed of entirely fatty acids and having a considerable amount of fat were imported from abroad, there is no regulatory basis for control of fatty acid composition and consumption is continuing without knowing the level of the products. Although, there are so many different varieties of vegetable oil brands in our markets and all of them labelled to be cholesterol-free. Due to increasing awareness of the health implications of high cholesterol in diets, most people now prefer to purchase cholesterol-free vegetable oils [9].

Therefore, the present investigation filled the knowledge gap on fatty acid profile and cholesterol content of commercially sold commonly consumed vegetable oils in Dire Dawa, Adama, and Addis Ababa, Ethiopia. The level of cholesterol was measured using a UV-visible spectrophotometer according to Liebermann-Burchard and Highperformance liquid chromatography (HPLC) method. Whereas the fatty acid compositions of selected oils were estimated using gas chromatography (GC-FID).

\section{Material and methods}

\subsection{Materials}

Corn oil, Hamaressa oil, Nigger seed oil, Modjo oil, Rapeseed oil, Peanut oil, Sunflower oil (local), Sunflower oil (imported, 3liter), Sunflower oil (imported, 1liter), Soybean oil (local), Soybean oil (imported), Sesame oil.

\subsection{Experimental design}

In this study, the term imported vegetable oil (IVO) is used to indicate edible vegetable oils that are imported from outside, branded vegetable oil (BVO) is used to indicate vegetable oil produced from registered industries in Ethiopia with brand name labelled on the product purchased from the market, while unbranded vegetable oil (UVO) refer to the locally produced edible vegetable oils without a brand, they were obtained specifically from their raw materials processed in small scale in different area around dire Dawa, Adama and Addis Ababa. Sources of edible vegetable oils (EVOs) sold in the market of Ethiopia include both imported as well as derived from local oil seeds. Samples of twelve brands of vegetable oils (Table 1) produced from a variety of oilseeds were purchased from Dire Dawa, Adama, and Addis Ababa Market, under various brand names. 
Table 1 Oil samples (information obtained from packaging or from producers)

\begin{tabular}{|l|l|l|l|l|l|}
\hline No & Code & Name of oil & $\begin{array}{l}\text { Type of } \\
\text { oil }\end{array}$ & Origin & Information \\
\hline 1 & MD & Modjo oil & BVO & Ethiopia & Combined oil produced from rapeseed and cotton \\
\hline 2 & V3L & Viking oil & IVO & Imported & Viking soyaben oil imported from Malaysia \\
\hline 3 & AV3 & Avena oil & IVO & Imported & Avena palm oil imported from Indonesia \\
\hline 4 & PN & Pennat oil & BVO & Ethiopia & Pennunet oil produced in Ethiopia \\
\hline 5 & TS & Tena soya & BVO & Ethiopia & Soyaben oil produced in Ethiopia \\
\hline 6 & VS1 & Viking soya & IVO & imported & Soybean oil produced in Malaysia \\
\hline 7 & NG & Nigger oil & UVO & Ethiopia & Hagere oil extracted from Nigger oil \\
\hline 8 & CN & Corn oil & IVO & imported & Crystal corn oil produced in Egypt \\
\hline 9 & HM & Hammaresa oil & BVO & Ethiopia & $\begin{array}{l}\text { Combined edible oil from rapeseed, cotton seed, } \\
\text { produced in Ethiopia }\end{array}$ \\
\hline 10 & SS & Sesame oil & BVO & Ethiopia & $\begin{array}{l}\text { Sesame oil produced by China edible oil processing } \\
\text { factory in Ethiopia }\end{array}$ \\
\hline 11 & SN1 & Sunflower & BVO & Imported & Sunflower seed produced in Ethiopia \\
\hline 12 & SN2 & Sunflower & UVO & Ethiopia & Endalek sunflower oil produced in Ethiopia \\
\hline
\end{tabular}

Each edible oil sample grouped into three sets. The first group was locally produced branded oil (UVO) obtained from an Ethiopian oil factory. The second group was branded imported oils (IVO) and the third was known branded locally produced in small (BVO). These were purchased as packaged by plastic and glass bottles and stored in a dark place under room temperature in the laboratory until it was required for analysis.

\subsection{Analytical determination method}

\subsubsection{Cholesterol estimation}

Liebermann-Burchard method

Cholesterol content was estimated using the Liebermann-Burchard procedure [9]. In this reaction, the acetic acid reacts with cholesterol in the oil sample to give a green colour, whose absorbance can be determined by a UV-Visible spectrophotometer at $640 \mathrm{~nm}$ [10]. Standard cholesterol solution was used as $2000 \mathrm{mg} / \mathrm{L}$ stock. The LiebermannBurchard reagent was prepared with $7 \mathrm{~mL}$ concentrated sulfuric acid and $5 \mathrm{~mL}$ glacial acetic acid and was covered with black paper and kept in an ice bucket in a dark place.

Preparation of sample solutions and standard cholesterol solutions

Five volumetric flasks were prepared and marked as S1, S2, S3, S4 and S5. Standard cholesterol solution was added as $0.5,1,1.5$, and $2 \mathrm{~mL}$ into five volumetric flasks whereas, flask five was kept blank. $2 \mathrm{~mL}$ of the Liebermann-Burchard reagent was added to all five volumetric flasks and diluted by adding chloroform $\left(\mathrm{CHCl}_{3}\right)$ until its final volume reaches $7 \mathrm{~mL}$ (Table 2). The flasks were covered with black carbon paper and kept in the dark for 15 minutes. Then, the spectrophotometer was set to zero with the blank (S5) at $640 \mathrm{~nm}$. The absorbance of all standards was determined on SP65 UV/Vis spectrophotometer and the standard graph was plotted.

Table 2 Liebermann-Burchard method for cholesterol estimation.

\begin{tabular}{|l|l|l|l|l|l|}
\hline Reagent (ml) & S1 & S2 & S3 & S4 & S5 \\
\hline Standard cholesterol solution & 0.5 & 1.0 & 1.5 & 2.0 & 0 \\
\hline Liebermann-Burchard reagent & 2 & 2 & 2 & 2 & 2 \\
\hline Chloroform & 4.5 & 4 & 3.5 & 3.0 & 5 \\
\hline Total volume & 7 & 7 & 7 & 7 & 7 \\
\hline
\end{tabular}


Determination of cholesterol content by Liebermann-Burchard method

Each sample solution (3 ml) was taken and subjected to absorbance measurement using SP65 UV/Vis spectrophotometer after adding $1 \mathrm{~mL}$ oil sample, $2 \mathrm{~mL}$ Liebermann-Burchard reagent and $4 \mathrm{~mL}$ chloroform. The cholesterol concentration of sample solutions was determined using a standard curve constructed graphically plotting the absorbance against $\mathrm{mg} / \mathrm{L}$ cholesterol.

\subsubsection{High performance liquid chromatography (HPLC) method}

Preparation of sample solutions and standard cholesterol solutions

Four volumetric flasks were prepared and marked as S1, S2, S3, and S4. Standard cholesterol solution was prepared as $10,20,50 \mu \mathrm{g} / \mathrm{L}$ concentration and each standard was added into the three volumetric flasks prepared above. But the last flask (flask 4) was kept blank. Each flask was covered with aluminum foil. The absorbance of all standards was determined on Agilent 1100 series, HPLC and standard graphs were plotted. Determination of cholesterol content by HPLC method

The oil samples were first saponified with 3\% ethanolic $\mathrm{KOH}$ and the resulting non-saponifiable parts of each sample were dissolved in chloroform and the analysis was carried out immediately. The HPLC analysis was done using an Agilent 1100 series, C18 column $(250 * 4.0 \mathrm{~mm}, 5 \mu \mathrm{m})$, acetonitrile/water (1:1) mobile phase and a UV detector at 239 $\mathrm{nm}$ at a flow rate of $0.4 \mathrm{ml} / \mathrm{min}$.

\subsubsection{Fatty acid determination}

Fatty acid methyl esters (FAME) were prepared by Methanolic Borontriflouride (13-15\%) following ISO 5509:2000(E) procedures and analyzed as soon as possible. The fatty acids of the sample oils were determined by gas chromatography (GC) using a GC1000 Dani (Italy, 2002) chromatograph equipped with an auto sampler and Flame Ionization Detector (FID) following ISO 15304:2003(E). The peaks were identified in comparison with the GC-MS data of standard oil. The GC-MS data of standard oil was first compared with the modern GC-MS library and the fatty acids it contains were identified. The obtained retention time of standard oil run on GC-FID standardized with respect to the GC-MS and the percentage composition of FAME prepared from standard oil was determined. The obtained relative retention times of FAME of sample oil run on GC-FID and GC-MS analysis of Standard oil was compared to determine the percentage compositions of FAME of each oil sample.

\subsection{Statistical Data Analysis}

The data obtained from the experiment was subjected to analysis using statistical software, SPSS (Statistical Package for Social Sciences) version 13.0. Tests for significance in variations were conducted by one-way analysis of variance (ANOVA) and the means were compared using Tukey Honestly Significant Difference test (Tukey HSD). Variations were considered significant at $\mathrm{p}<0.05$.

\section{Results and discussion}

The determination of cholesterol and fatty acid composition of commercially available sample oils were carried out. The obtained results are tabulated and discussed hereunder:

\subsection{Estimation of cholesterol content}

\subsubsection{Construction of calibration curve}

The absorbance of standard cholesterol solution is shown in Table 3. The equation of the calibration curve was obtained from the resulting absorbance versus concentration (mg/L) curve (Figure 1): $y=0.00384 x-0.03543: R^{2}=0.97725$

Table 3 Absorbance of standard cholesterol solutions.

\begin{tabular}{|l|l|}
\hline Concentration (mg/L) & Absorbance \\
\hline 71.43 & $0.295 \pm 0.000$ \\
\hline 142.86 & $0.526 \pm 0.001$ \\
\hline 214.29 & $0.714 \pm 0.011$ \\
\hline 285.72 & $0.949 \pm 0.003$ \\
\hline
\end{tabular}




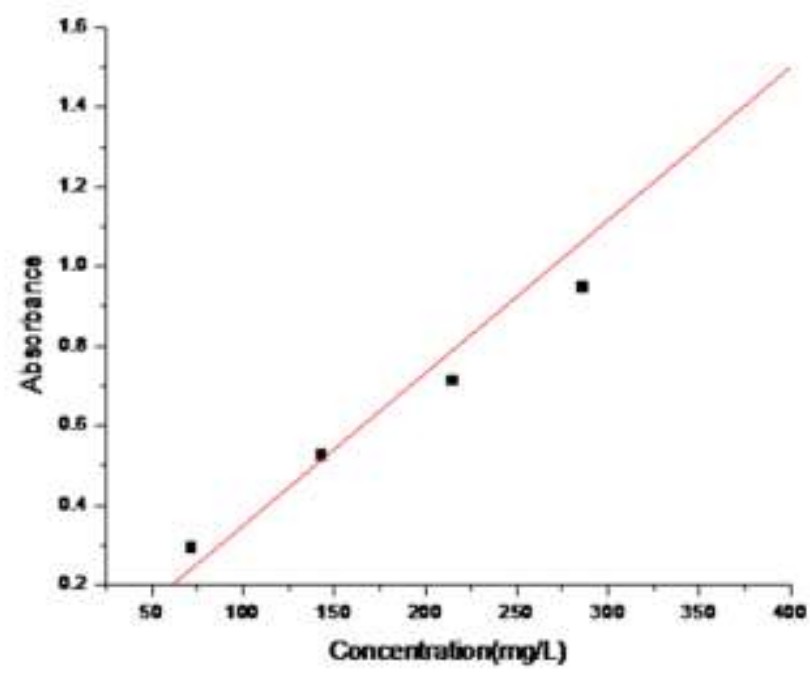

Figure 1 Calibration curve using cholesterol standard.

The peak areas of standard cholesterol solution are indicated in Table 4. The equation of the calibration curve was obtained from the resulting peak area versus concentration (mg/L) curve (Figure 2): $y=11.6 \mathrm{x}-61: \mathrm{R}^{2}=0.99458$

Table 4 Peak area of standard cholesterol solutions.

\begin{tabular}{|l|l|}
\hline Concentration $(\mathbf{m g} / \mathbf{L})$ & Peak area in $\mathbf{m A U}$ \\
\hline 10 & 156 \\
\hline 20 & 321 \\
\hline 50 & 634 \\
\hline
\end{tabular}

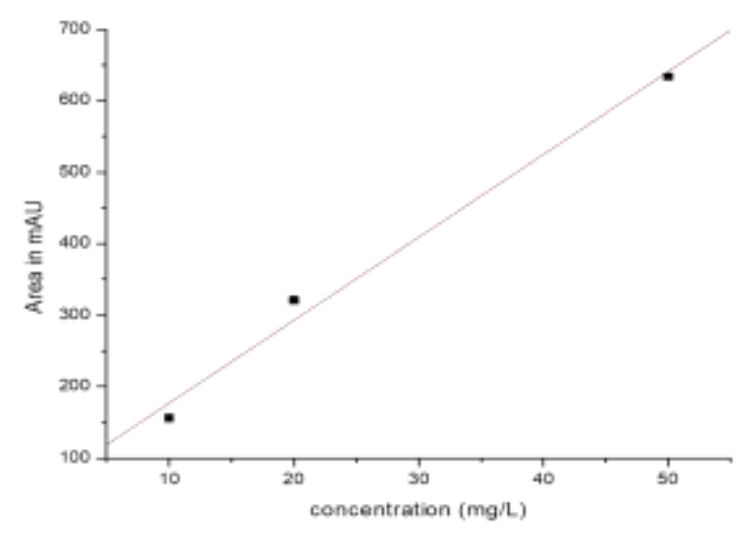

Figure 2 Calibration curve using cholesterol standard.

\subsubsection{Cholesterol composition}

The analytical data for the cholesterol content of twelve vegetable oil samples were shown in Table 5.Out of these, ten oil samples contained cholesterol (Annex 3). Among these unbranded sunflower oil (SN2) has significantly $(\mathrm{p}<0.05)$ the highest cholesterol concentration $(24.31 \pm 0.85)$ and Modjo oil (MD) contained the lowest cholesterol concentration $(0.78 \pm 0.16 \mathrm{mg} / \mathrm{L})$. Surprisingly, the Peanut oil (PN) and nigger seed (NG) oils contained nil cholesterol concentration. Values of cholesterol content in different vegetable oil groups were recorded in the following ascending order: $\mathrm{NG}=\mathrm{PN}$ $<\mathrm{MD}<\mathrm{AV} 3<\mathrm{CN}<\mathrm{V} 3 \mathrm{~L}<\mathrm{VS} 1<\mathrm{TS}<\mathrm{SN} 1<\mathrm{OL}<\mathrm{HM}<\mathrm{SS}<\mathrm{SN} 2$. The mean cholesterol content analyzed for all vegetable oil samples collected was significantly different $(\mathrm{p}<0.05)$ from each other. 
Table 5 Cholesterol compositions of sample oils.

\begin{tabular}{|c|c|c|c|c|}
\hline \multirow[t]{2}{*}{ Number } & \multirow[t]{2}{*}{ Code } & \multicolumn{2}{|c|}{ Cholesterol content in $\mathrm{mg} / \mathrm{L}$} & \multirow[t]{2}{*}{ Type of oil } \\
\hline & & Liebermann-Burchard & HPLC methods & \\
\hline 1 & MD & ND & $0.78 \pm 0.16$ & BVO \\
\hline 2 & $\mathrm{~V}_{3} \mathrm{~L}$ & ND & $2.66 \pm 0.19$ & IVO \\
\hline 3 & AV3 & ND & $1.26 \pm 0.12$ & IVO \\
\hline 4 & PN & ND & ND & BVO \\
\hline 5 & TS & ND & $4.68 \pm 0.00$ & BVO \\
\hline 6 & VS1 & ND & $3.42 \pm 0.14$ & IVO \\
\hline 7 & NG & ND & ND & UVO \\
\hline 8 & $\mathrm{CN}$ & $0.57 \pm 0.00$ & $1.41 \pm 0.14$ & IVO \\
\hline 9 & $\mathrm{HM}$ & $0.43 \pm 8.25$ & $14.74 \pm 0.28$ & BVO \\
\hline 10 & SS & $5.10 \pm 2.35$ & $14.96 \pm 0.39$ & BVO \\
\hline 11 & SN1 & $2.04 \pm 0.12$ & $5.74 \pm 1.13$ & BVO \\
\hline 12 & SN2 & $4.39 \pm 0.39$ & $24.31 \pm 0.85$ & UVO \\
\hline
\end{tabular}

\subsection{Discussion on cholesterol compositions}

There are so many different varieties of vegetable oil brands in our markets and all of them claimed to be cholesterolfree. Cholesterol has been known as the 'oily killer' since the early-mid 60s, especially since several works then showed that it is the main cause of atherosclerotic lesions which are the major causes of coronary heart disease [11, 12]. Due to increasing awareness of the health implications of high cholesterol in our diets, most people now prefer to purchase cholesterol-free vegetable oils [9, 13]. People consume different varieties of vegetable oils directly or as their food ingredients. From the present study, it was evident that the vegetable oils had different cholesterol levels. In an earlier study conducted by Dimberu et al. (2011) reported that rapeseed oil contained significantly the highest cholesterol concentration ( $257.1 \pm 0.42 \mathrm{mg} / \mathrm{L})$ while branded palm oil has the least concentration $(88.8 \pm 0.85 \mathrm{mg} / \mathrm{L})$ of cholesterol. They recorded varying cholesterol content in cottonseed oil, $80 \%$ cottonseed $+20 \%$ rapeseed oil, rapeseed both branded and non-branded oils, olive oil, palm oil, sunflower oil and nigger seed oil by the method of LiebermannBurchardin Bahir Dar, Ethiopia. The values obtained in the present investigations except for nigger seed oil (NG) are lower than the earlier reported values [14]. The estimated cholesterol composition of the named oil sample was also lower than the earlier reported works done outside Ethiopia [15].

Table 6 Cholestrol concentration of some selected oils as reported by Dimberu et al. (2011).

\begin{tabular}{|l|l|l|}
\hline Oil samples & Cholesterol concentration & $\begin{array}{l}\text { Cholesterol concentration estimated } \\
\text { in this study }\end{array}$ \\
\hline Rapeseed oil (unbranded) & $257.1 \pm 0.42 \mathrm{mg} / \mathrm{L}$ & $14.74 \pm 0.28$ \\
\hline Rapeseed oil (branded) & $139.20 \pm 0.28 \mathrm{mg} / \mathrm{L}$ & Not done \\
\hline palm oil & $88.8 \pm 0.85 \mathrm{mg} / \mathrm{L}$ & $1.26 \pm 0.12$ \\
\hline $80 \%$ cottonseed $+20 \%$ rapeseed oil & $190.60 \pm 0.28 \mathrm{mg} / \mathrm{L}$ & $0.78 \pm 0.16$ \\
\hline Sunflower oil & $204.60 \pm 1.13 \mathrm{mg} \mathrm{L}-1$ & $24.31 \pm 0.85$ \\
\hline Nigger seed oil & ND & ND \\
\hline
\end{tabular}

The present work also showed comparative cholesterol contents of imported vegetable oil (IVO) against industrial processed BVO and small scale processed UVOs. The cholesterol concentration of oil produced in Ethiopia and classified 
as the BVOs was lower than UVO except for nigger seed oil (NG) and peanut oil (PN). However, the estimated value in BVO except for Modjo oil (MD) and peanut oil (PN) was higher than that of IVOs, and the variations were statistically significant $(\mathrm{p}<0.05)$.

Our findings from this study support the previous work by Shukla et al. (2002), which showed that cholesterol is present in vegetable oils, although in a small proportion, (up to $5 \%$ of the total sterol). This provides supportive information for quality monitoring of edible vegetable oils that are used for foodstuff. With an exception for nigger seed (NG) and peanut oil (PN) oils most the oil samples contained cholesterol. The HPLC, due to its sensitivity confirms that there is really no cholesterol-free oil in our markets as it is advertised by producers.

This finding contradicts the label claim by most of the producers of these vegetable oils. It is pertinent that oil producers and marketers should label their products correctly with the quantity of their cholesterol in the oil brand no matter how minute the quantity therein. It is then left to the consumers to make up their minds which oil brand satisfies their culinary needs.

\subsection{Estimation of fatty acid content}

\subsubsection{Experimental results}

Table 7 showed the fatty acid compositions of edible oil samples. But figure 3. 4 and 5 showed selected fatty acid and methyl esters obtained from the gas chromatographic analysis. The analyzed profile is for 12 edible oil samples.

Table 7 Fatty acid composition of analyzed vegetable oils (in g FA/ $100 \mathrm{~g}$ oil).

\begin{tabular}{|c|c|c|c|c|c|c|c|c|c|c|c|c|}
\hline \multirow[b]{2}{*}{ Fatty Acid } & \multicolumn{12}{|c|}{ Oil Samples } \\
\hline & HM & MD & AV3 & VS3 & VS1 & TS1 & SN1 & SN2 & $\mathrm{PN}$ & SS & NG & $\mathrm{CO}$ \\
\hline Myristic C14:0 & ND & 0.45 & 0.77 & 0.09 & 0.08 & 0.09 & 0.09 & ND & 0.32 & 0.08 & 0.03 & 0.05 \\
\hline Palmitic C16:0 & 2.97 & 15.22 & 38.33 & 9.34 & 10.88 & 10.83 & 6.08 & 8.8 & 8.21 & 6.73 & 8.79 & 8.79 \\
\hline Palmitoleic C16:1(n-7) & ND & 0.31 & ND & 0.09 & ND & 0.09 & 0.06 & ND & ND & 0.09 & ND & 0.06 \\
\hline Stearic C18:0 & 1.22 & 2.17 & 4.41 & 3.91 & 4.69 & 4.04 & 3.43 & 5.45 & 4.05 & 3.52 & 3.74 & 2.66 \\
\hline Oleic C18:1(n-9) & 20.88 & 41.51 & 52.46 & 25.14 & 27.78 & 24.03 & 88.84 & 40.72 & 44.44 & 65.43 & 31.94 & 25.43 \\
\hline Linoleic C18:2(n-6) & 15.92 & 17.84 & 3.46 & 52.45 & 55.65 & 59.54 & ND & 43.54 & 30.75 & 21.8 & 45 & 61.73 \\
\hline$\alpha$-Linolenic C18:3(n3) & 1.27 & 0.5 & ND & ND & ND & ND & ND & ND & ND & 0.2 & 0.33 & 0.33 \\
\hline Arachidic C20:0 & 0.97 & 0.61 & 0.36 & 1.29 & 0.35 & 0.7 & 0.54 & 0.66 & 3.36 & 0.38 & 1.72 & 0.34 \\
\hline Paullinic C20:1(n-9/7) & 8.94 & 3.75 & 3.42 & 1.8 & 0.22 & 0.03 & ND & 0.44 & 3.39 & 0.21 & 1.95 & 0.3 \\
\hline Behenic C22:0 & 0.81 & 0.44 & ND & 2.64 & 0.32 & ND & 0.34 & 0.4 & 3.84 & 0.76 & 3.28 & 0.49 \\
\hline Erucic C22:1(n-9) & 46.12 & 16.7 & 0.05 & 3.17 & ND & 0.47 & ND & ND & ND & ND & ND & ND \\
\hline Lignoceric Acid C24:0 & ND & ND & ND & ND & ND & ND & ND & ND & 1.34 & ND & ND & ND \\
\hline Nervonic C24:1(n-9) & 0.81 & ND & ND & ND & ND & ND & ND & ND & 0.29 & ND & 1.98 & ND \\
\hline
\end{tabular}

\subsection{Fatty acid compositions}

The results of fatty acid detected in oil samples showed Palmitic acid (C16:0), Arachidic acid (C20:0) and stearic acid (C18:0) were common in all saturates except in sunflower oil (SN1). Oleic (C18:1) and linoleic acids (C18:2) observed in all unsaturated FAs of oils. Palmitic acid (C16:0) was predominant acid in Avena palm oil (AV3) detected as $38.33 \%$. The level detected was in the range specified for palmitic acid (34.0-74.0\%) in the Codex Standard. The high composition of palmitic acid makes palm oil (AV3) good oil for the deep frying process, and an excellent source for blending oils for achieving specific properties for several uses, a source of margarine and bakery products application. 


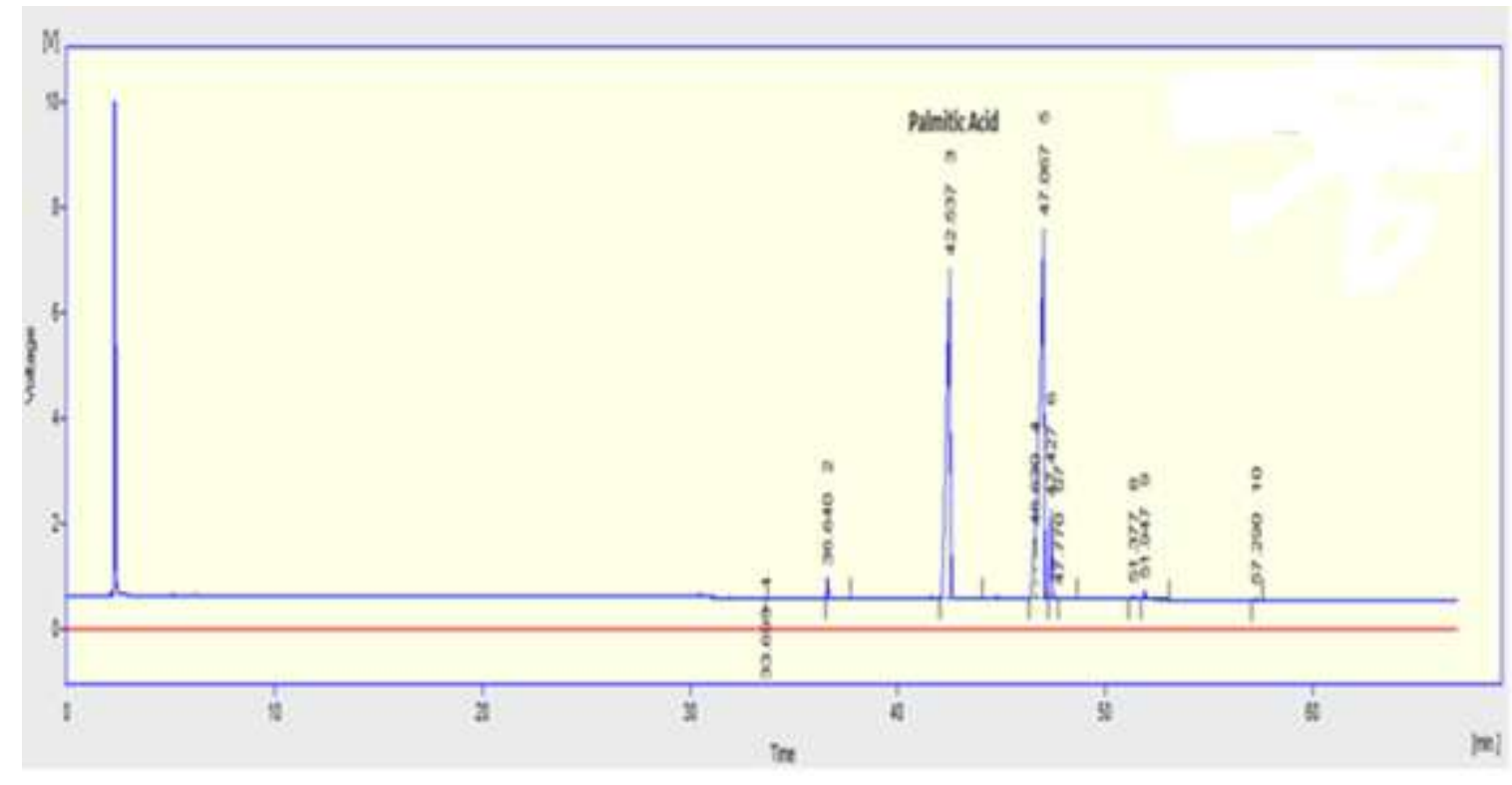

Figure 3 Gas Chromatogram of fatty acid methyl esters of AV3

Myristic acid (C14:0) was detected in all oil samples ranging from $0.03 \%$ ( nigger oil (NG)) to $0.77 \%$ (Avena palm oil (AV3)) except for Hamaressa (HM) and sunflower oils (SN2). The presence of Arachidic acid was also identified in all oil samples and its relatively higher in Peanut oil (PN). Palm oil (AV3) and soya bean oil (TS1) didn't contain behenic acid (C22:0). On the other hand, the presence of lignoceric acid (C24:0) was found only in the tested samples of peanut oil PN (1.34\%). This result was nearer to the previous report made by Zambiazi et al. (2007). Peanut oil showed the highest long-chain SFA content, comprising of arachidic (C20:0), behenic (C22:0) and lignoceric FA (C24:0).

Oleic acid (C18:1 9c) was predominant in sunflower oil (SN1 (88.84\%)) (Figure 1) and sesame oil (SS (65.43\%)). The oleic acid content in the sesame oil is above the range specified in the Codex standard (35.90-42.30\%) but the content in the sunflower oil (SN1) sample analyzed was within the range for high oleic sunflower seed oil [75$90.7 \%]$.

From nutritional point of view, the presence of oleic acid in diet is very useful. It has been shown that oleic acid is effective in lowering LDL content and LDL cholesterol content. Also, oleic acid reduces blood pressure, increases fat burning to help with weight loss, protects cells from free radical damage, prevents ulcerative colitis and generates brain myelin [16].

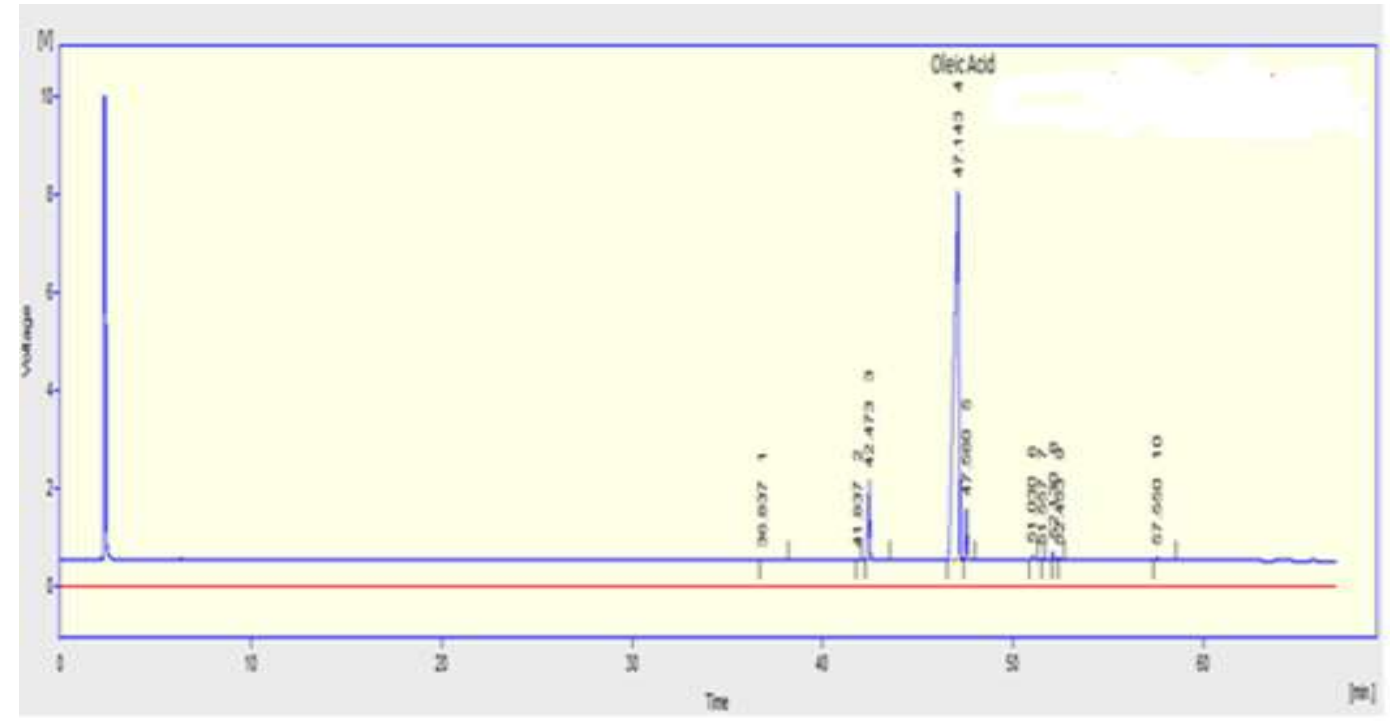

Figure 4 Gas Chromatogram of fatty acid methyl esters of sunflower seed oil (SN1) 
The GC data showed that linoleic acid (C18:2 6c) was the major fatty acid in soybean oils (VS1, VS3, TS) (52.45 - 59.54\%), corn oil (CO) (61.73\%) and sunflower oil (SN2) (43.54\%). The level detected was in the appropriate ranges for linoleic acid specified in the Codex Standard for soybean (48.00-59.00\%) and corn oils (34.00-65.60\%) but lower for sunflower oil (SN2) (48.30-74.00\%) [17].

Both oleic (C18: $19 \mathrm{c}$ ) and linoleic acids (C18:2 6c) were found together chiefly in sunflower (SN2), peanut (PN) and nigger oils (NG). The percent composition of oleic and linoleic acid obtained in sunflower oil (SN2) was 40.72\% and $43.54 \%$ respectively, which is almost close to the higher range specified for oleic (14.00-39.40\%) and below the range for linoleic acid (48.30-74.00\%) in sunflower seed oil in the Codex standard. The level of oleic acid in the peanut (PN) and nigger oils (NG) was $44.44 \%$ and $31.94 \%$ respectively. This result is found in the range specified for the named oils. The values of linolenic acid composition for peanut (PN) and nigger oils (NG) were 30.75\% and 45.00\% respectively.

Among tested oils, a high concentration of alpha-Linolenic acid (Omega-3) was detected in Hamaressa oil (1.27\%) and Modjo oil (0.50\%), which improves the Omega 6/Omega 3 ratio in the diet. The alpha-Linolenic acid composition for nigger oil (NG), corn oil (CO) and sesame oil (SS) are $0.33 \%, 0.33 \%$ and $0.20 \%$ respectively. This value was lower than the range specified in the codex standard for Hamaressa oil (HM) and Modjo oil (MD). Omega 3 may contribute to a reduced risk of fatal Ischemic Heart Disease (IHD) through its antiarrhythmic effect in cell culture studies.

Erucic acid (EA), commonly named cis-13-docosenoic acid, is a typical example of very-long-chain mono-unsaturated fatty acids. Erucic acid (C22:1 9c) was a chief fatty acid found in the Hammaressa oil (HM) samples detected as 46.12\% which is in the range of specified for erucic acid content in rapeseed oils (2.0-60.0\%). The major source of EA is the high-erucic-acid seed oils of the Cruciferae family, which includes rapeseed, mustard and wallflower. All contained about $45 \%$ to $60 \%$ EA [18]. Higher levels of erucic acid are unsuitable for human consumption for food purposes in both European Union and other developed countries since they showed serious pathological changes in the heart and skeletal in animals $[19,20]$. The presence of high erucic acid in oils is considered anti-nutritional, as it has been reported to cause lipidosis in children and myocardial fibrosis in monkeys [21]. Higher consumption of erucic acid may increase the concentration of adrenal cholesterol causing fibrotic changes in the myocardium, liver weight and cholesterol [22].

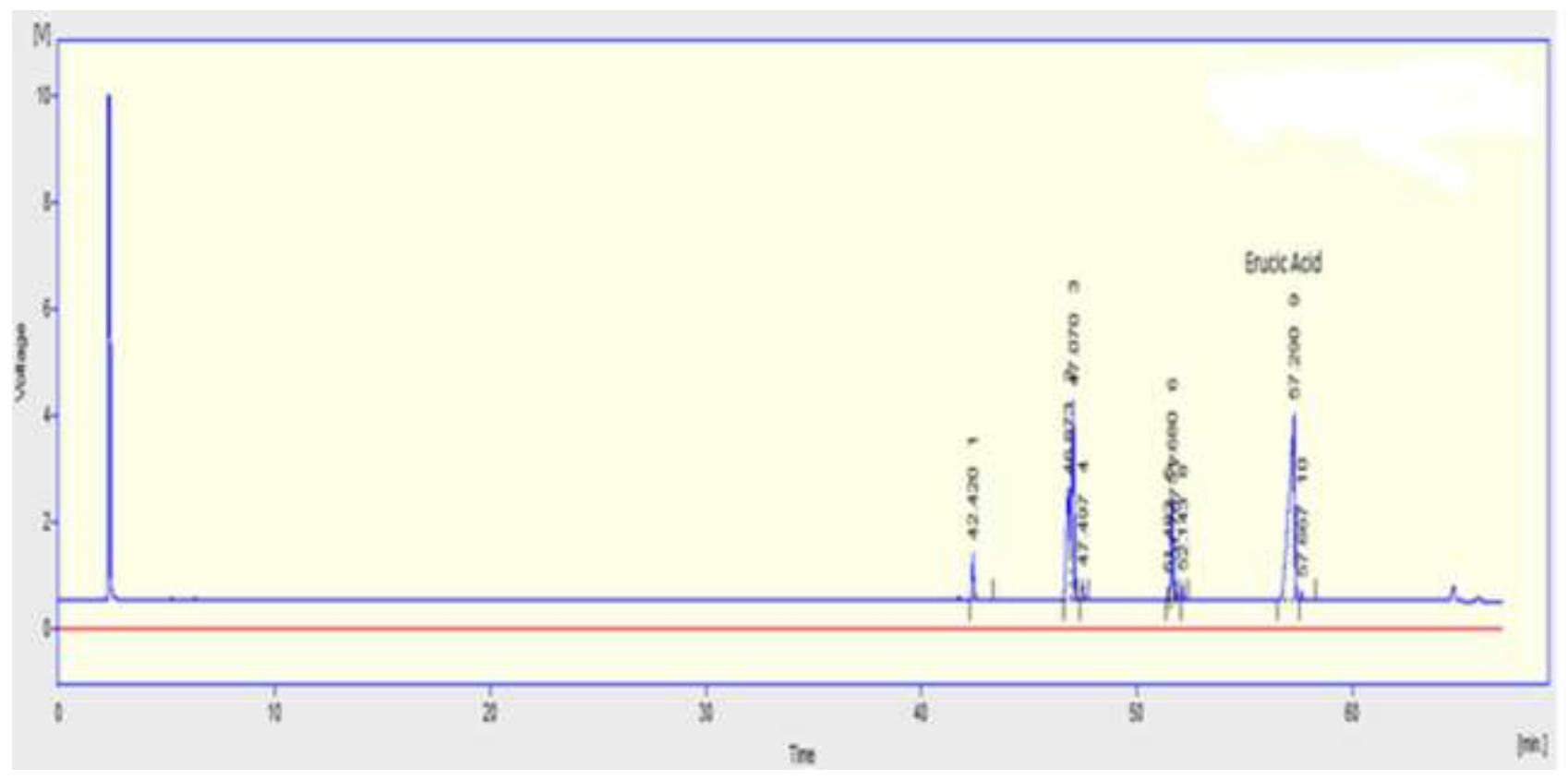

Figure 5 Gas Chromatogram of fatty acid methyl esters of Hamaressa oil (HM)

\subsubsection{The total fatty acid ratio}

The World Health Organization (WHO) recommends polyunsaturated fatty acid (PUFA)/saturated fatty acids (SFA) ratio of 0.8 to 1.0 and linoleic acid (Omega 6) alpha-linolenic acid (Omega 3) ratio of 5-10 in the diet (WHO/FA0, 2003). The American Heart Association recommends total fat intake to less than 25-35 percent of total calories. A saturated fatty acid (SFA) intake of not more than 10 percent of total calories, a monounsaturated fatty acid(MFA) intake in the range of 10-15 percent and polyunsaturated fats up to 10 percent of total calories.

The mean of total SFA, MFA, polyunsaturated fatty acids (PUFA) and the values of polyunsaturated/saturated indexes 
$(\mathrm{P} / \mathrm{S})$ are shown in Table 8. The results from this study showed that the percentage of the total SFA ranged from $5.97 \%$ for Hammaresa oil (HM) to 43.87\% for palm oil (AV3), with the predominant presence of palmitic acid (C16:0) and stearic acid (C12:0). These findings were similar to previously reported results [23]. All samples contained SFA less than one-fifth of the total FA content except Avena palm oil (AV3). It is known that excessive consumption of SFA is related to the increase of the plasmatic cholesterol and obesity [24].

Peanut, nigger and Modjo oils contained SFA in the range of 18 to $25 \%$ that can be taken as a good source for cooking and short term frying process, due to their relatively higher saturated fatty acid content, and consequently higher stability. Of $43 \%$ of the SFA found in palm oil, above $50 \%$ is palmitic acid. This composition makes palm oil a good oil for the deep frying process, and an excellent source for blending oils for achieving specific properties for several uses, as a source of margarine and bakery products application [25].

Table 8 Fatty acid ratio of oil samples.

\begin{tabular}{|l|l|l|l|l|l|l|l|l|l|}
\hline $\begin{array}{l}\text { Oil } \\
\text { samples }\end{array}$ & SFA & MUFA & PUFA & $\begin{array}{l}\text { PUFA/SF } \\
\text { (PS) }\end{array}$ & $\begin{array}{l}\text { omega } \\
\mathbf{- 9}\end{array}$ & $\begin{array}{l}\text { omega- } \\
\mathbf{6}\end{array}$ & $\begin{array}{l}\text { omega- } \\
\mathbf{3}\end{array}$ & $\begin{array}{l}\text { omega-6 } \\
\text { /omega-3 }\end{array}$ & Predominant \\
\hline HM & 5.97 & 76.75 & 17.19 & 2.88 & 20.88 & 15.92 & 1.27 & 12.54 & Erucic Acid \\
\hline MD & 18.89 & 62.27 & 17.84 & 0.94 & 41.51 & 17.84 & 0.5 & 35.68 & Oleic Acid \\
\hline AV3 & 43.87 & 55.93 & 3.46 & 0.079 & 52.46 & 3.46 & - & - & palmitic\& oleic \\
\hline VS3 & 17.27 & 30.2 & 52.45 & 3.037 & 25.14 & 52.45 & - & - & Linoleic Acid \\
\hline VS1 & 16.32 & 28 & 55.65 & 3.41 & 27.78 & 55.65 & - & - & Linoleic Acid \\
\hline TS1 & 15.66 & 24.62 & 59.54 & 3.80 & 24.03 & 59.54 & - & - & Linoleic Acid \\
\hline SN1 & 10.48 & 88.9 & ND & ND & 88.84 & ND & - & - & Oleic Acid \\
\hline SN2 & 15.31 & 41.16 & 43.54 & 2.84 & 40.72 & 43.54 & - & - & oleic \&Linoleic \\
\hline PN & 21.12 & 48.12 & 30.75 & 1.46 & 44.44 & 30.75 & - & - & oleic \& Linoleic \\
\hline SS & 11.47 & 65.73 & 22 & 1.92 & 65.43 & 21.8 & 0.2 & 109 & Oleic Acid \\
\hline NG & 17.56 & 35.87 & 45.33 & 2.58 & 31.94 & 45 & 0.33 & 136.36 & Linoleic \& oleic \\
\hline CO & 12.33 & 25.79 & 62.06 & 5.03 & 25.43 & 61.73 & 0.33 & 187.06 & Linoleic Acid \\
\hline
\end{tabular}

The total MFA percentage composition of oil samples ranged from 25.79\% (corn oil) to 88.90\% sunflower oil (SN1). Oleic acid is predominantly found in all MFA except Hammaressa and modjo oils. These oils contain high amount of erucic acid (C20:1).Monounsaturated fatty acids are highest in sunflower oil (SN1) (88.9\%) followed by Hamaressa oil (HM) (76.75\%), sesame oil (SS) (65.73\%), Modjo oil (MD) (62.27\%), and palm oil (AV3) (55.93\%). In recent years there has been an interest in MUFA as a suitable replacement for saturated fatty acids. There net effect on serum lipids and proteins is not much different from PUFA but they are not as susceptible to oxidation which may play a role in artherogenesis [26].

The PUFA fatty acids (lionoleic and linolenic) detected in all oil samples except in sunflower oil (SN1). The percentage composition of linoleic acid ranges from $3.46 \%$ of palm oil (AV3) to $62.06 \%$ of corn oil (CO). The total unsaturated fatty acids were higher in all oils except in palm oil (AV3).

The consumption of PUFA and MUFA has been recommended to improve the lipid profile in relation to the saturated fatty acid. Yu-Pothet al. (2000) indicated that the rich diets in PUFA may provoke an increase in the LDL - cholesterol oxidation and the reduction of the HDL -cholesterol levels. There is a tendency to increase MUFA consumption, that seems not to affect the HDL levels and also it may reduce the LDL and triacylglycerols blood levels. The sum result of this consumption makes it more effective in prevention of hearth diseases.

Olive oil is nutritionally considered one of the best salad vegetable oil due to the highest MUFA content (75\% -77 \%), which is mainly due to the predominant presence of oleic acid (C18:1). Our investigations of FA composition sample oils showed that the content of MUFA in sunflower (SN1) and sesame oils were $88.90 \%$ and $65.73 \%$ respectively. 


\subsubsection{Recommended dietary ratios of Omega-6 to Omega-3 and PUFA to SFA}

The relationship between saturated and polyunsaturated FA content is expressed as P/S index. The values of P/S indexes of tested oils were shown in Table 8. This value is an important parameter for determination of nutritional value of certain oils. Oils and fats with higher value of $\mathrm{P} / \mathrm{S}$ index than 1 are considered to have nutritional value. The higher value of $\mathrm{P} / \mathrm{S}$ index was found for corn oil (CO) (5.03\%) and the lowest for palm oil (AV3) (0.079\%) and Modjo oil (MD) (0.94\%). For most oil samples the P/S index was above one except palm oil (AV3) and Modjo oil (MD). Several studies indicated that higher value of $\mathrm{P} / \mathrm{S}$ index means a smaller deposition of lipids in the body [27].

The World Health Organization (WHO) recommended that the ratio of linoleic acid (Omega-6) /alpha linolenic acid (Omega-3) is 5-10\% in the diet (WHO, 2003). Only Hammaresa oil (HM) (12.54\%) provided the optimal closest ratio of Omega- 6 to Omega-3 ratio of 5-10\% (Table 8) as recommended by World Health Organization (WHO). The remaining oils had either very high or low omega- 6 to omega- 3 ratio. Excessive amounts of Omega- 6 polyunsaturated fatty acids and very high Omega-6/Omega-3 ratios promote the pathogenesis of many diseases, including cardiovascular diseases, cancer, inflammatory diseases and autoimune diseases [28].

\subsubsection{Comparison between the same varieties}

The fatty acid composition of two sunflower and three soyabeean oil samples were studied and the result showed that locally produced crystal sunflower oil (SN1) contain high content of oleic acid (88.84\%) and imported sunflower oil (SN2) contained high linolenic acid (43.54\%). This result leads to conclude that the two types of sunflower oils were different in their varieties. But the fatty acid composition of the three varieties of soybean oils (VS3, VS1, TS) was found similar.

\section{Conclusion}

This study disproves that the producers and marketers claim the oil they produced is cholesterol-free with the exception of Nigger seed (NG) and Peanut (PN) oils. The HPLC, due to its high sensitivity confirms that there is no real cholesterolfree oil in our markets as advertised. This provides supportive information for quality monitoring of edible vegetable oils that are used for foodstuff. In consideration of the total percentage of unsaturated fatty acids (MUFA+PUFA), most oils contained a high amount of unsaturated fatty acids except palm oil (AV3) and peanut oil (PN). Hammaresa oil (HM) and Modjo oil (MD) even if they contained a high amount of unsaturated fatty acid, the higher levels of erucic acid were unsuitable for human consumption for food purposes. On the other hand concerning the total percentage of essential fatty acids (linoleic and linolenic) corn and nigger oils are better. But the composition of alpha-linolenic acid was lower than the range specified in codex standards for all oils. On overall consideration, corn oil, nigger oil, soybean oils and sunflower (high linoleic-low oleic variety) oil are suitable for mass consumption to combat malnutrition. The lower saturated and higher monounsaturated fatty acid content makes sesame oil, peanut oil and sunflower (high oleic acid) nutritionally more adequate than soybean oil for salad and cooking purpose. For general consumption, the fatty acid composition of nigger seed, sesame and corn oil contains a healthy mixture of all the types of saturated and unsaturated fatty acids. The value of the $\mathrm{P} / \mathrm{S}$ index which is associated with the impact on human health is also high for the above named-oils, which makes them the most suitable edible oils for mass consumption. In general, no single oil could meet all the requirement of these recommendations but some are in close agreement with the recommendations.

\section{Compliance with ethical standards}

Ethics approval was not required for this research.

\section{Acknowledgments}

I would like to acknowledge Dire Dawa University for financial support and Addis Ababa University for running GCMS analysis for our samples.

\section{Disclosure of conflict of interest}

The authors hereby declare there is no conflict of interests. 


\section{References}

[1] Pryde, E.H.; Carlson, K.D. Trends in industrial usage for vegetable oils - symposium overview. Journal of the American Oil Chemists' Society. 1985; 62(5): 916-917.

[2] Gül MK; Amar S. Sterols and the phytosterol content in oilseed rape (Brassica napus L.). Journal of Cell \& Molecular Biology. 2006; 5(2): 71-79

[3] Kamal-Eldin A; Moazzami A. Plant Sterols and Stanols as Cholesterol-Lowering Ingredients in Functional Foods. Recent Patents on Food, Nutrition \& Agriculture. 2009;1(1): 1-14.

[4] Andersson B; Caroline WPD; Francinete RC; Fabio S; Cesar A; Antonio GF. A simple methodology for the determination of fatty acid composition in edible oils through ${ }^{1} \mathrm{H}$ NMR spectroscopy. Magnetic Resonance Chemistry. 2010; 48: 642-650.

[5] El-Beltagi HS; Salama Z A; El-Hariri DM. Evaluation of fatty acids profile and the content of some secondary metabolites in seeds of different flax cultivars (linum usitatissimum l.). Genetics applied plant physiology. 2007; 3(4): 187-202.

[6] Dzisiak D. New Oils Reduce Saturated and Trans Fats in Processed Foods.Cereal Foods World. 2004; 49(6): 331333.

[7] Lawton C; Delargy H; Brockman J; Smith F; Blundell J. The degree of saturation of fatty acids influences postingestive satiety. British Journal of Nutrition, 2000; 83(5): 473-482. doi:10.1017/S000711450000060X

[8] Zambiazi RC; Przybylski R; Zambiazi MW; Mendonça CB. Composição em ácidos graxos de óleos e gorduras vegetais. Boletim do Centro de Pesquisa de Processamento de Alimentos. 2007; 25(1): 111-120.

[9] Attarde D; Pawar J; Chaudhari B; Pal S. Estimation of sterols content in. edible oil and ghee samples. International Journal of Pharmaceutical Sciences Review and Research. 2010; 5: 135 -137.

[10] Almajidi M. Estimation of Cholesterol Content and Free Fatty Acids in Edible Oils in Iraq. International Journal of Chemical and Physical Sciences. 2015; 4 (5): 80-91.

[11] Nicolosi RJ; Woolfrey B; Wilson IA; Scolin P; Handelman G; Fisher R. Decreased aortic early atherosclerosis and associated risk factors in hypercholesterolemic hamsters fed a high- or mid-oleic acid oil compared to a highlinoleic acid oil. The Journal of Nutritional Biochemistry. 2004; 15(9): 540-547.

[12] Okpuzor J; Okochi VI; Ogbunugafor HA; Ogbonnia S; Fagbayi T; Obidiegwu C. Estimation of Cholesterol Level in Different Brands of Vegetable Oils. Pakistan Journal of Nutrition. 2009; 8(1): 57-62.

[13] Dakasha A; Jaywant P; Bhagyashree C; Subodh P. Estimation of sterols content in edible oil ande ghee samples. Electronic Journal of Environmental, Agricultural and Food Chemistry. 2010; 9(10): 1593-1597.

[14] Dimberu GA; Belete B. Estimation of total free fatty acid and cholesterol content in some commercial edible oils in Ethiopia, Bahir Dar. Journal of Cereals and Oil seeds. 2011; 2(6): 71-76.

[15] Alison Lee A; Thurnham D; Chopra M. Consumption of tomato products with olive oil but not sunflower oil increases the antioxidant activity of plasma. Free Radical Biology and Medicine. 2000; 29(10): 1051-1055. doi.org/10.1016/S0891-5849(00)00440-448.

[16] Kim Margarette CN; Hyoun JK; Yehyun L;Yan Z; Jia Y; Dong HL; Xiang ZL; Stephen BS; Hyun AS; Seong HC. High dietary oleic acid in olive oil-supplemented diet enhanced omega-3 fatty acid in blood plasma of rats. Food science and nutrition. 2020; 8(7):3617-3625. https://doi.org/10.1002/fsn3.1644

[17] Standard for Named Vegetable Oils Codex-Stan 210-1999. Codex Alimentarius. 2001; 8:11-25. Adopted in 1999. Revision: 2001, 2003, 2009. Amendment: 2005, 2011, 2013 and 2015.

[18] Sonntag NOV. Erucic, behenic: feedstocks of the 21st century. INFORM. 1991; 5: 449-463.

[19] Food Standards Australia New Zealand. Erucic acid in food: A toxicological review and risk assessment. Tech. Report Series. 21:1448-3017,2003.

[20] Kramer JK; Farnworth ER; Thompson BK; Corner AH; Trenholm HL. Reduction of myocardial necrosis in male albino rats by manipulation of dietary fatty acid levels. Lipids. 1982; 17(5): 372-382.

[21] Ackman RG; Eaton CA; Sipos JC; Loew FM; Hancock D. A Comparison of Fatty Acids from High Levels of Docosenoic Acids of Rapeseed Oil (Erucic Acid) and of Partially Hydrogenated Fish Oil (Primarily Cetoleic Acid) in a Non-Human Primate Species in a Short-Term Exploratory Study. Nutrition \& Dietetics. 1977; 25: 170-185. 
[22] Beare-Rogers JL; Nera EA; Craig BM. Accumulation of cardiac fatty acids in rats fed synthesized oils containing $\mathrm{C}_{22}$ fatty acids. Lipids.1972; 7: 548-552.

[23] Zambiazi RC; Przybylski R; Zambiazi MW; Mendonca CBB. Fatty acid composition of vegetable oils and fats. CEPPA Curitiba. 2007; 25(1): 111-120.

[24] Ristic V; Ristic G. Role and importance of dietary polyunsaturated fatty acids in the prevention and therapy of atherosclerosis. Medicinski Pregled. 2003; 56 (1-2): 50 - 53

[25] Mckenzie S; Taylor DC. Seed oils: a new age. Plant Biotechnology. 1996; 1(1): 1-4.

[26] Yu-Poth S; Etherton TD; Reddy CC; Pearsno TA; Reed R; Zhao. Lowering dietary saturated fat and total fat reduces the oxidative susceptibility of LDL in healthy men and women. Journal of Nutrition. 2000;130(9): 2228- 2237.

[27] Pandya G; Nagarnaik M; Sarjoshi A; Dhakulkar A; Manke A; Khanal B. An assessment of chemical and nutritional analysis of some food samples in urban city. Asian Journal of Research in Chemistry. 2015; 8(2): 108-112. DOI : 10.5958/0974-4150.2015.00019.X

[28] Simopoulos, A.P, The importance of the ratio of omega-6/omega-3 essential fatty acids. Biomed pharmacther. 2002; 56: 365-379. 